Surface and Coatings Technology 140 (2001) pp. 51-57.

Copyright ( 2001 Elsevier Science B.V. All rights reserved.

doi:10.1016/S0257-8972(01)01003-9

ISSN: 0257-8972

\title{
Effects of chromate and chromate conversion coatings on corrosion of aluminum alloy 2024-T3
}

\author{
J. Zhao $^{\mathrm{a}}$, L. Xia ${ }^{\mathrm{a}}$, A. Sehgal ${ }^{\mathrm{b}}$, D. Lu ${ }^{\mathrm{b}}$, R.L. McCreery ${ }^{\mathrm{a}}$, G.S. Frankel ${ }^{\mathrm{b}}$
}

Department of Chemistry, The Ohio State University, Columbus, OH 43210, USA Department of Materials Science and Engineering, The Ohio State University, 477 Watts Hall, 2041 College Rd., Columbus, OH 43210, USA

\begin{abstract}
Various effects of chromate conversion coatings (CCCs) and chromate in solution on the corrosion of AA2024-T3 and pure Al are studied in this work. Raman spectroscopy was used to investigate the nature of chromate in CCCs through a comparison with the spectra of known standards and artificial $\mathrm{Cr}(\mathrm{III}) / \mathrm{Cr}(\mathrm{VI})$ mixed oxides. Chromate was shown to be released from CCCs and to migrate to and protect a nearby, uncoated area in the artificial scratch cell. However, experiments investigating the effect of chromate in solution on anodic dissolution kinetics under potentiostatic control indicated that large chromate concentrations were needed to have an effect.
\end{abstract}

Keywords: Corrosion; Conversion coating; Aluminum; Chromate

\section{Introduction}

Chromates are extremely effective and widely used as corrosion inhibitors for high strength Al alloys in aerospace applications. A combination of pressures, including environmental regulations on the use and handling of chromates, increased service-life requirements of the fleet of airplanes, and the cost of preventive maintenance, has motivated the US Air Force to invest in efforts to find improved and environment-friendly methods of corrosion protection. A number of replacements for chromate conversion coatings (CCCs) have been developed in recent years, but none are as effective at inhibiting corrosion, especially for the high-strength Al alloys commonly used in aerospace applications [1]. An Air Force Blue Ribbon Advisory Panel on Aircraft Coatings concluded that developing a better understanding of the mechanisms of aluminum corrosion and chromate inhibition is a top priority and a prerequisite for the development of a successful chromate replacement [2]. The work reported in this communication is part of a larger effort to investigate the role of chromate in inhibition of high-strength $\mathrm{Al}$ alloys.

As a result of various research efforts over many years, considerable understanding of the mechanisms of Al corrosion and the inhibition provided by chromate has already been developed. Exposure of Al to a dichromate-containing $\mathrm{CCC}$ solution results in simultaneous oxidation of $\mathrm{Al}$ and reduction of the chromate to $\mathrm{Cr}(\mathrm{III})[3,4]$ : 


$$
\begin{aligned}
& 2 \mathrm{Al} \rightarrow 2 \mathrm{Al}^{3+}+6 \mathrm{e}^{-} \\
& \mathrm{Cr}_{2} \mathrm{O}_{7}^{2-}+8 \mathrm{H}^{+}+6 \mathrm{e}^{-} \rightarrow 2 \mathrm{Cr}(\mathrm{OH})_{3}+\mathrm{H}_{2} \mathrm{O}
\end{aligned}
$$

Chromate is retained in the CCC $[3,4]$. Indirect evidence from, for instance, salt spray tests indicates that it is possible for the chromate in the CCC to promote self-healing of damaged areas by dissolving into a local defect and altering the local environment and dissolution kinetics. Other evidence that chromate retained in CCCs is an important part of the mechanism of corrosion protection also exists. For instance, exposure of CCC-treated samples to $\mathrm{NaCl}$ [4] or salt spray [5] resulted in a decrease in the $\mathrm{Cr}(\mathrm{VI})$ content of the film and an increase in the $\mathrm{Cr}$ (III) content. Any comparison of a substitute for CCCs must take this unique property into consideration.

In summary, the mechanism for chromate inhibition of $\mathrm{Al}$ alloy dissolution is that chromate is a very soluble, higher-valent, oxidizing ion $\left(\mathrm{CrO}_{4}{ }^{2-}\right.$ or $\left.\mathrm{Cr}_{2} \mathrm{O}_{7}{ }^{2-}\right)$ with a lower-valent form that is insoluble and creates an extremely protective film $\left[\mathrm{Cr}_{2} \mathrm{O}_{3}\right.$ or $\left.\mathrm{Cr}(\mathrm{OH})_{3}\right]$. Localized corrosion is extinguished by chromate reduction according to Eqs. (1) and (2). Chromate can cause self-healing of defects by migrating from a distance. Despite this agreed-upon description of the inhibition phenomenon, several key unresolved issues remain:

1. What is the structure, composition, and formation mechanism of CCCs?

2. How, and at what rate, is chromate released from CCCs and primers?

3. Does chromate in CCCs and primers have a role other than dissolving and migrating to corrosion sites?

4. Does chromate in a primer affect the properties of the primer?

5. What is the speciation of chromium ions in solution?

6. How do chromates inhibit localized corrosion?

7. How do they affect anodic and cathodic kinetics of the Al matrix and common intermetallic particles?

8. How do they affect passivation and passive film properties?

9. Does chromate improve the adhesion of organic coatings?

This paper addresses some of these issues by summarizing previously presented findings. The influence of chromate on pit growth is studied by the thin film pit-growth technique. Raman spectroscopy is used to investigate the release and migration of chromate from CCCs and also the chemistry of CCCs by comparison with various synthetic mixed oxides composed of $\mathrm{Al}(\mathrm{III})$, $\mathrm{Cr}(\mathrm{III})$, and $\mathrm{Cr}(\mathrm{VI})$ species. The effect of released chromate is studied by electrochemical methods.

\section{Experimental}

Samples of AA2024-T3 were mounted in epoxy and polished to 1200 grit in DI water. CCC films were formed by immersion in a solution of $1.51 \mathrm{~g}$ of Alodine powder in $200 \mathrm{ml}$ of nanopure water, adjusted to $\mathrm{pH} 1.69$ with $\mathrm{HNO}_{3}$. After rinsing, the CCC samples were dried and aged in air for 10 days, unless stated otherwise.

Details of the Raman spectroscopy are given in previous publications [6,7]. Synthetic mixed oxides were made by dissolving $\mathrm{Al}(\mathrm{III}), \mathrm{Cr}(\mathrm{III})$ and $\mathrm{Cr}(\mathrm{VI})$ species into solution and then 
precipitated by increasing the $\mathrm{pH}$. A mixed $\mathrm{Cr}(\mathrm{III}) / \mathrm{Cr}(\mathrm{VI})$ oxide was precipitated from a mixture of $\mathrm{Cr}\left(\mathrm{NO}_{3}\right)_{3}$ and $\mathrm{K}_{2} \mathrm{Cr}_{2} \mathrm{O}_{7}$. An $\mathrm{Al}(\mathrm{III}) / \mathrm{Cr}(\mathrm{VI})$ oxide was precipitated from a mixture of $\mathrm{Al}\left(\mathrm{NO}_{3}\right)_{3}$ and $\mathrm{K}_{2} \mathrm{Cr}_{2} \mathrm{O}_{7}$.

The release of chromate from a CCC was studied by Raman spectroscopy using the set-up shown in Fig. 1. A 2024-T3 sample with a small hole was given a CCC treatment. A 1-ml droplet of $0.1 \mathrm{M} \mathrm{NaCl}$ was placed onto the sample, and the chromate released from the CCC into the droplet was monitored by Raman using a laser beam that passed through the droplet and through the hole in the sample.

The effect of chromate migration from a CCC-coated surface to an uncoated surface, similar to what might be seen in a scratched sample exposed to a salt spray environment, was studied with the use of a new cell that can be considered an 'artificial scratch' cell. A CCCcoated sample was placed in close proximity $(1.8 \mathrm{~mm}$ gap) to a freshly polished and untreated $\mathrm{Al}$ alloy sample, Fig. 2. In some cases, the two electrodes were electrically connected, and in other cases, an O-ring was used to seal the electrolyte from air. The presence of any $\mathrm{Cr}$ on the surface of the untreated electrode or any change in its properties would be a result of migration of a $\mathrm{Cr}$ species from the CCC-coated sample.

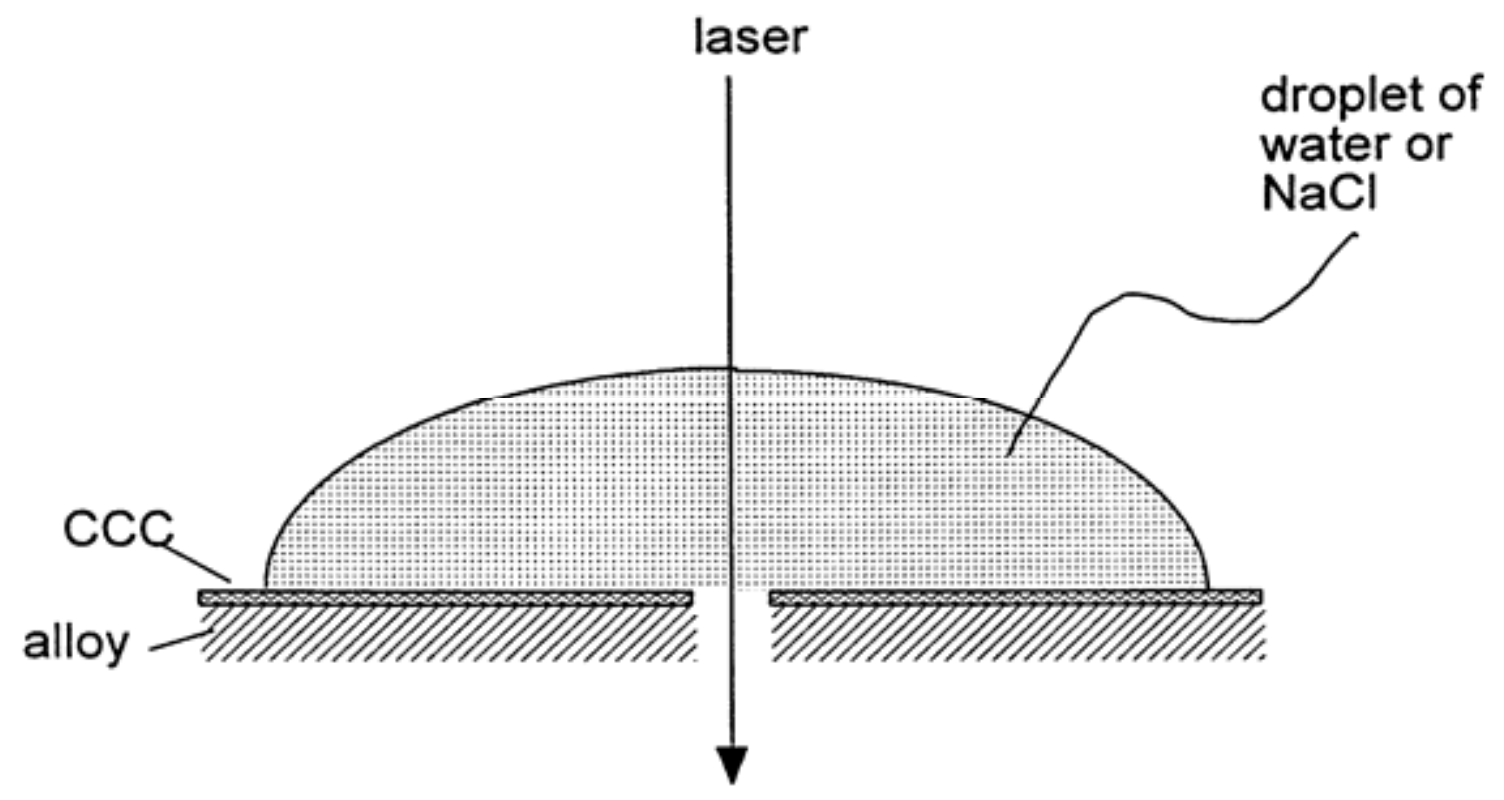

Fig. 1. Schematic representation of the approach used to measure release of chromate from CCCs on AA2024-T3 using Raman spec-troscopy. 


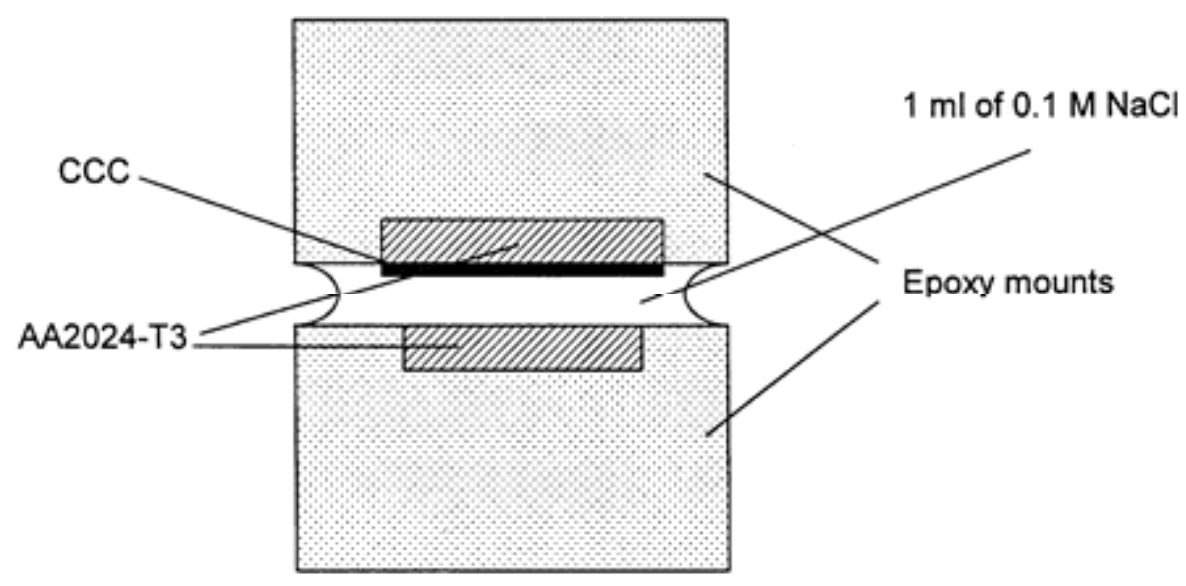

Fig. 2. Schematic drawing of artificial scratch cell.

Pit growth in thin metallic films deposited on inert substrates has been found to be an interesting approach to the study of pit growth [8-12]. Details of the experimental approach are available in the previous publications [8-12]. In brief, pits in thin films grow in a twodimensional fashion, with a current density that is constant with time. The pit current density can be easily and accurately determined by analysis of images of growing pits using Faraday's law. 


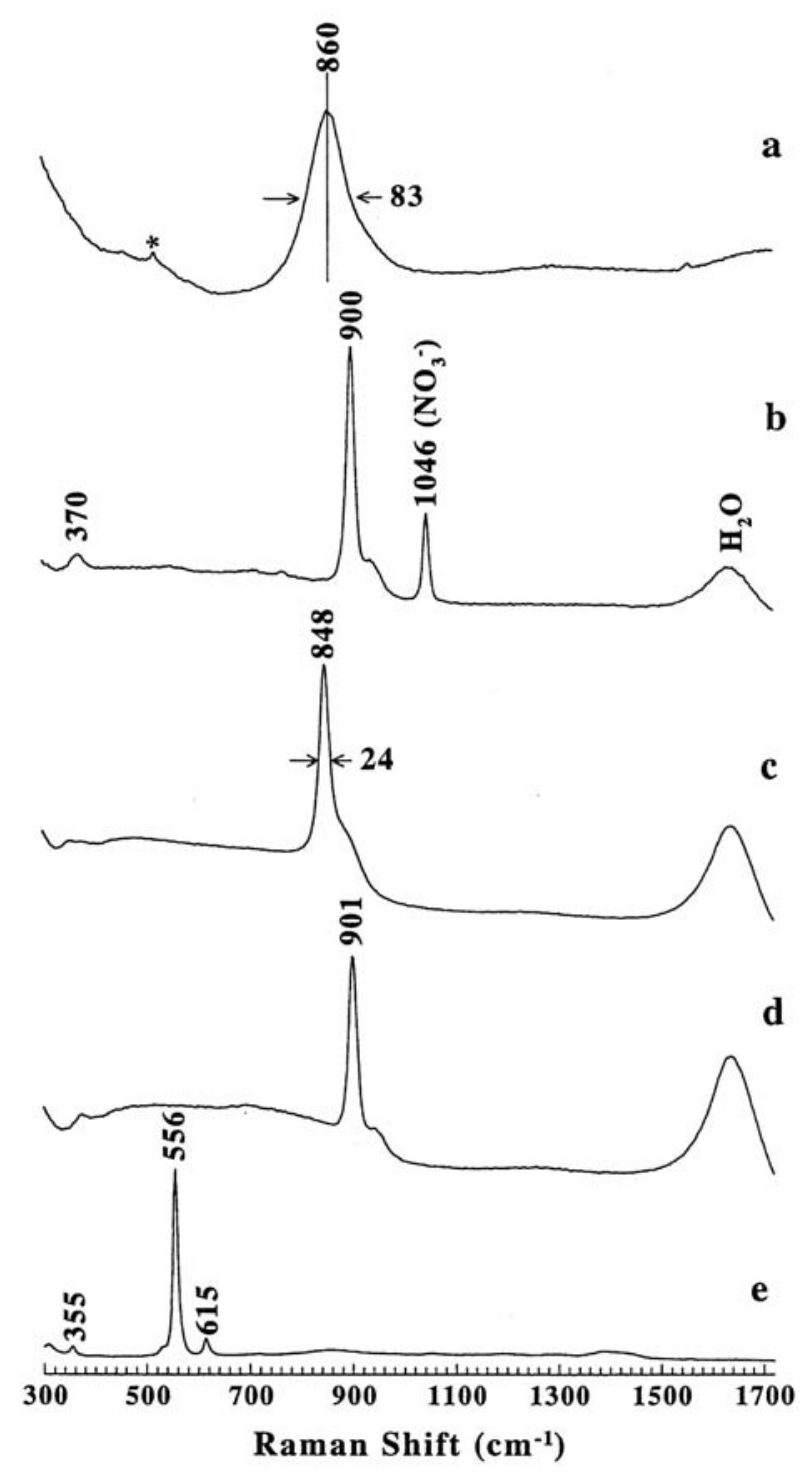

Fig. 3. Raman spectra of: (a) CCC; (b) Alodine solution; (c) $8.6 \times 10^{-3} \mathrm{M} \mathrm{K}_{2} \mathrm{CrO}_{4}$; (d) $4.2 \times 10^{-3} \mathrm{M}$ $\mathrm{K}_{2} \mathrm{Cr}_{2} \mathrm{O}_{7}$; and (e) $\mathrm{Cr}_{2} \mathrm{O}_{3} / \mathrm{H}_{2} \mathrm{O}$ paste. Scale for each spectrum is arbitrary. Reprinted with permission of the Electrochemical Society [6].

\section{Results and discussion}

Raman spectroscopy clearly distinguishes different $\mathrm{Cr}^{6+}$ species in solution, Fig. 3. The Raman line for chromate (Fig. 3c) is shifted from the dichromate line (Fig. 3d) by over $50 \mathrm{~cm}^{-1}$. The spectrum for Alodine solution (Fig. 3b) is very similar to that of dichromate, which is to be expected, given the low $\mathrm{pH}$ of the Alodine solution. The Raman band for $\mathrm{Cr}_{2} \mathrm{O}_{3}$ (Fig. 3e) is at approximately $560 \mathrm{~cm}^{-1}$, but since $\mathrm{Cr}^{3+}$ species are not strong Raman scatterers, they are not easily distinguishable in the presence of strong Raman scatterers, such as $\mathrm{Cr}^{6+}$ species. Therefore, the absence of bands associated with $\mathrm{Cr}^{3+}$ species does not indicate that they are not present. An example is given by the spectrum for a CCC film on AA2024-T3 (Fig. 3a), which shows primarily $\mathrm{Cr}^{6+}$ species. This spectrum is primarily sensitive to the $\mathrm{Cr}^{6+}$ species, and shows 
that the CCC band is close to chromate, but is broadened. This may be the result of a dichromate component, or because the $\mathrm{CCC}$ is a polymeric oxide. The composition and structure of the $\mathrm{Cr}(\mathrm{III}) / \mathrm{Cr}(\mathrm{VI})$ mixed oxide and the CCC are discussed in more detail in [7].

The Raman spectra of a CCC coating and Alodine solution are shown again in Fig. 4 over a wider range of frequencies. A comparison with the spectra from two synthetic mixed oxides is also shown in this figure. The peak frequency for the CCC film is close to that for the $\mathrm{Cr}$ mixed oxide. Also, this frequency was constant at $858-859 \mathrm{~cm}^{-1}$ for the CCC film and the $\mathrm{Cr}$ mixed oxide as the $\mathrm{pH}$ was varied from 4 to 9.2. In contrast, the peak frequency for the $\mathrm{Al} / \mathrm{Cr}$ mixed oxide shifted from 879 to $845 \mathrm{~cm}^{-1}$ over that same $\mathrm{pH}$ range [7]. Furthermore, ICP analysis of the $\mathrm{CCC}$ indicated very little $\mathrm{Al}$ content (an $\mathrm{Al} / \mathrm{Cr}$ molar ratio of approx. 0.01). These observations suggest that the CCC is very similar in nature to the $\mathrm{Cr}(\mathrm{III}) / \mathrm{Cr}(\mathrm{VI})$ mixed oxide. This view is similar to that presented by Osborne, in which the CCC is described as a sol-gel, with the structure of the sol-gel being composed of a $\mathrm{Cr}$ (III) matrix and $\mathrm{Cr}(\mathrm{VI})$ species being trapped within the matrix [13]. However, the Raman data indicate that the tetrahedral chromate center is significantly perturbed in the CCC compared to its solution structure, probably indicating a covalent $\mathrm{Cr}(\mathrm{III})-\mathrm{O}-\mathrm{Cr}(\mathrm{VI})$ bond [7].

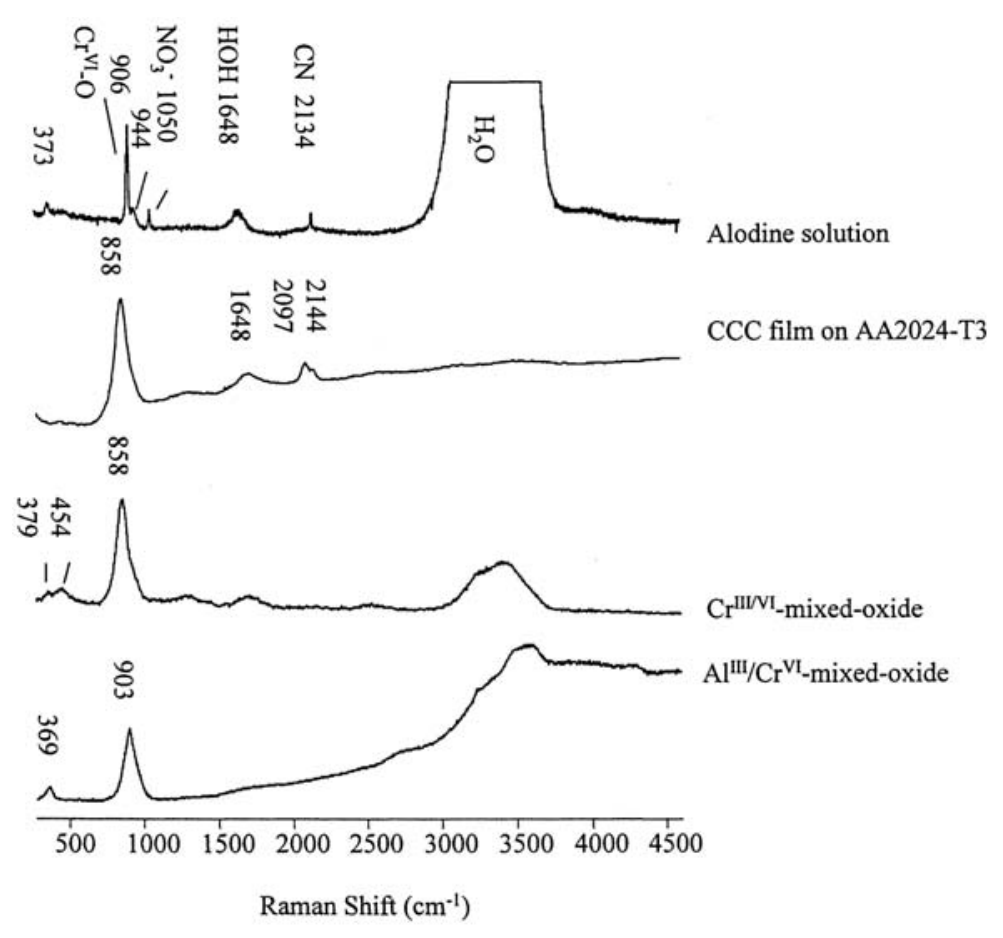

Fig. 4. Raman spectra of Alodine solution, CCC, and synthetic mixed oxides. Reprinted with permission of the Electrochemical Society [7].

The release of chromate from a CCC was investigated by Raman spectroscopy using the set-up shown in Fig. 1. Chromate was indeed found to be released from CCCs, and the Raman spectra of the released species appear to be very similar to that of potassium chromate in solution. The rate of release was dependent on the extent of aging in air prior to the experiment, Fig. 5. The rate of release for samples aged for $20 \mathrm{~min}$ and 10 days was $2 \times 10^{-7}$ and $7 \times 10^{-8}$ $\mathrm{g} / \mathrm{cm}^{2} \mathrm{~h}$, respectively, in terms of grains of released $\mathrm{CrO}_{4}{ }^{2-}$. The rate of release decreased with 
time and the concentration in the droplet seemed to saturate after a period. Details of this release process are being further investigated by UV absorption.

Now that the chemistry of CCCs and the release of chromate from them have been documented, the question arises as to the influence of the released chromate on bare Al alloy surfaces. The anecdotal evidence of the 'throwing power' or active inhibition of chromate at a scratch in a corrosive environment was investigated by means of the artificial scratch experiment described above. An XPS survey scan of an initially untreated sample after $20 \mathrm{~h}$ of exposure to the artificial scratch cell indicated the presence of $\mathrm{Cr}$ on the surface, Fig. 6. Sputtering of the surface resulted in removal of the $\mathrm{Cr}$.

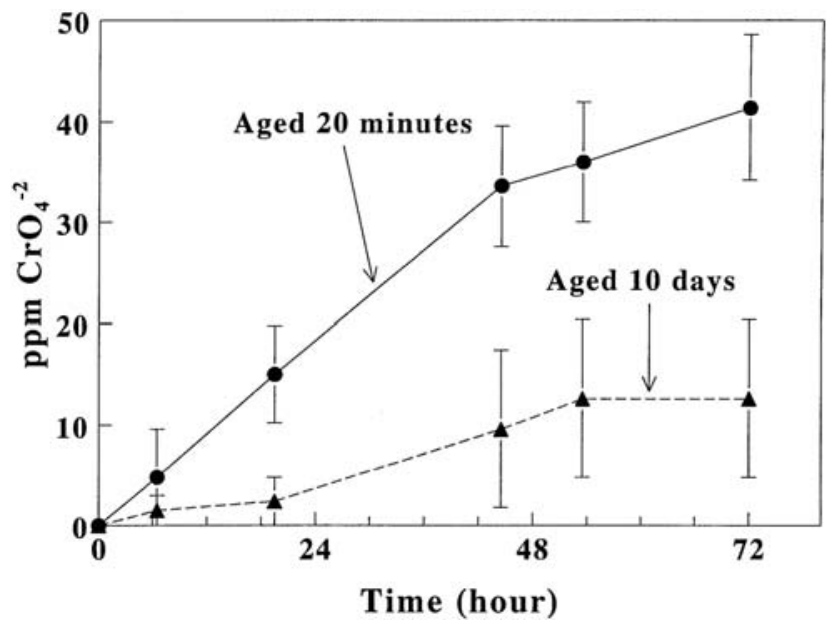

Fig. 5. Chromate released form $2.8 \mathrm{~cm} 2$ of CCC into $1 \mathrm{ml}$ of $0.1 \mathrm{M} \mathrm{NaCl}$ determined by Raman spectroscopy with the use of a calibration curve based on the $848-\mathrm{cm}-1$ band. Reprinted with permission of the Electrochemical Society [6].

The chromate that was released from the $\mathrm{CCC}$, migrated to the untreated surface, and deposited as some sort of layer resulted in corrosion protection. After exposure in the artificial scratch cell for $96 \mathrm{~h}$, the initially untreated sample exhibited little corrosion, with the polishing scratches still visible under a microscope. In contrast, a control sample exposed to the artificial scratch cell with neither sample CCC-coated was heavily corroded after $72 \mathrm{~h}$ of exposure. Quantitative measurements resulted in the same conclusion. The polarization resistance measured in $0.1 \mathrm{M} \mathrm{NaCl}$ after exposure to the artificial scratch cell for varying periods is shown in Fig. 7. The polarization resistance is seen to increase for the samples exposed to a cell with a CCC-treated sample.

An improvement in the resistance to localized corrosion is also evident for a sample exposed to a chloride solution containing very dilute chromate, Fig. 8. Fig. 9 shows a series of Raman spectra for a sample exposed to $0.1 \mathrm{M} \mathrm{NaCl}+8 \times 10^{-5} \mathrm{M} \mathrm{K}_{2} \mathrm{CrO}_{4}$ for 5 days across a line that intersected a small pit. The area of the analysis was approximately $50 \mu \mathrm{m}$ in diameter, and the sample was translated a distance of approximately $28 \mu \mathrm{m}$ between each spectrum. Where the analysis area intersected the pit, the spectrum indicates an enrichment of $\mathrm{Cr}(\mathrm{VI})$ species that is spectroscopically similar to the CCC. This enrichment is interesting in that it shows that chromate is concentrated in the region of a pit, exactly where it might be needed to inhibit further corrosion. 


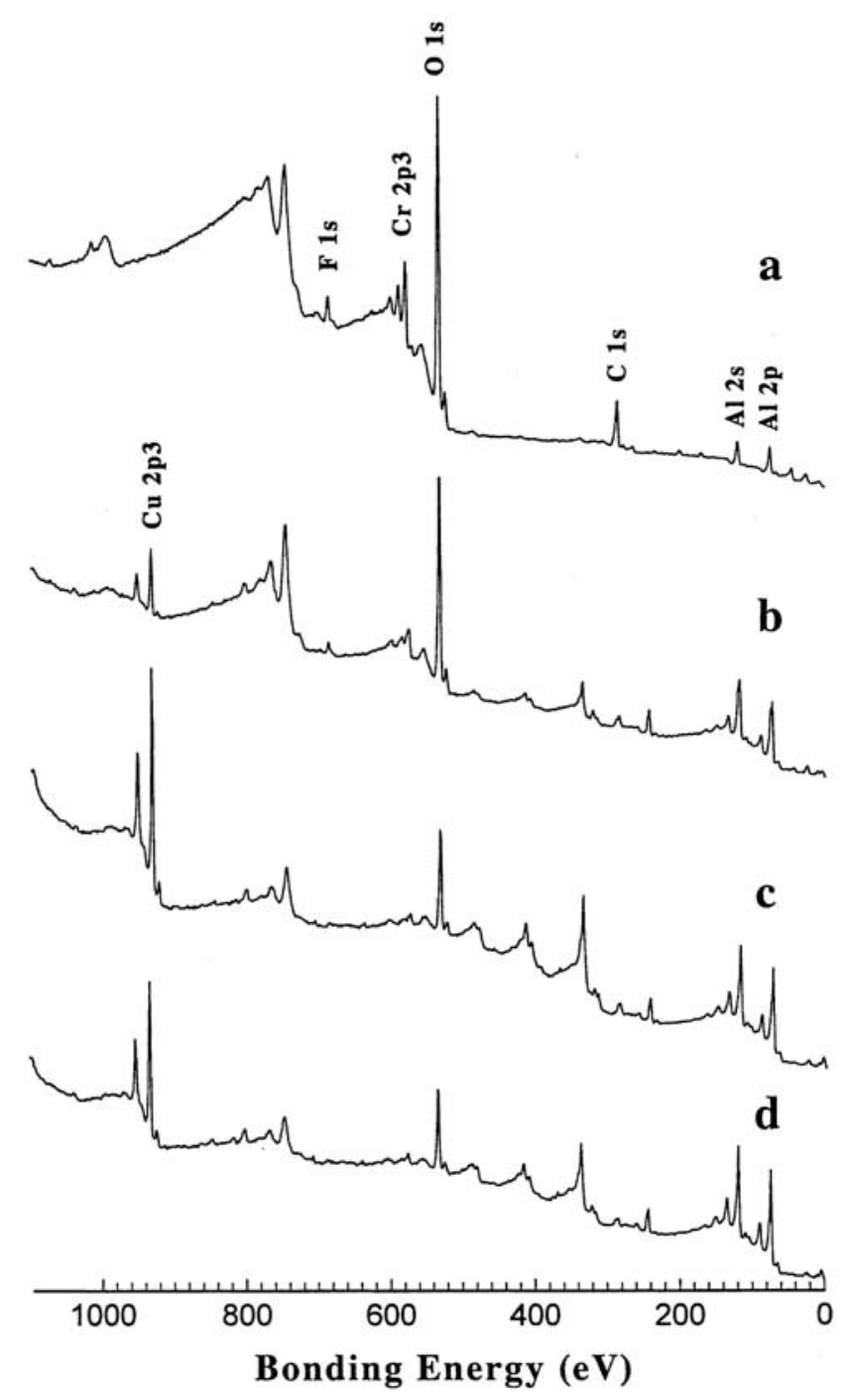

Fig. 6. XPS spectra of an initially untreated AA 2024-T3 sample exposed to the artificial scratch cell. (a) Initial spectrum, others are after Ar+ sputtering for: (b) 3; (c) 9; and (d) $18 \mathrm{~min}$. Reprinted with permission of the Electrochemical Society [6].

The influence of chromate on actively growing pits under potentiostatic control was investigated with the thin film pit-growth technique described above. Fig. 10 shows the pit polarization curves for 209-nm-thick $\mathrm{Al}$ films on glass in $1 \mathrm{M} \mathrm{NaCl}$ solutions containing a range of sodium dichromate concentrations. The pit current density is determined by analysis of images of the growing pits, and is typically constant at a fixed applied potential. Note that the current densities are extremely high, of the order of $10-100 \mathrm{~A} / \mathrm{cm}^{2}$. This is a result of the very small dimensions, and the resultant short diffusion length or ohmic path. The addition of $0.05 \mathrm{M}$ $\mathrm{Na}_{2} \mathrm{Cr}_{2} \mathrm{O}_{7}$ to $1 \mathrm{M} \mathrm{NaCl}$ results in a polarization curve that is actually somewhat higher than that for $1 \mathrm{M} \mathrm{NaCl}$ alone [12]. This may be a result of the increase in the conductivity of the electrolyte. 


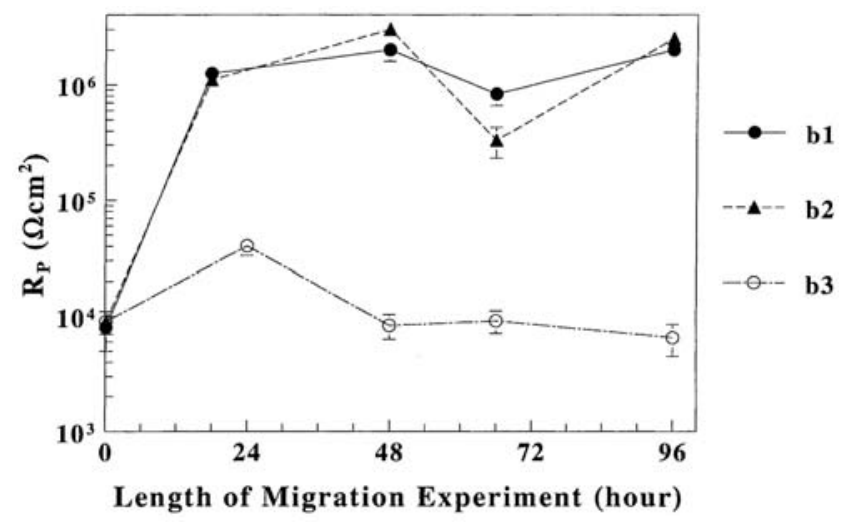

Fig. 7. Polarization resistance of AA2024-T3 in $0.1 \mathrm{M}$ $\mathrm{NaCl}$ after various exposure times in the artificial scratch cell. (b1) CCC on other sample; (b2) CCC on other sample and samples connected with a wire; and (b3) no CCC on either sample.

The addition of $2 \mathrm{M} \mathrm{Na}_{2} \mathrm{Cr}_{2} \mathrm{O}_{7}$ results in a significant decrease in the pit current density. An intermediate, but still quite large, concentration of $0.5 \mathrm{M} \mathrm{Na}_{2} \mathrm{Cr}_{2} \mathrm{O}_{7}$ results in a slight reduction in the pit current density. Polarization curves are given for 'fast' and 'slow' pits and for 'step-up' and 'step-down' polarization. The 'fast' pits had hydrogen bubbles at the pit perimeter, similar to the case with less or no dichromate added. Some pits or portions of the pit perimeter, however, grew slower because the undermined passive film was altered and became a barrier to mass transport. Hydrogen bubbles evolved at these surfaces were seen to travel along the glass surface and be emitted at some distance from the pit perimeter. This change in the passive film was a result of some interaction with the chromate in solution. Fast-growing pits exhibited a hysteresis in their pit polarization curve. The pit current density on the upward scan was higher than on the downward scan as a result of the formation of a precipitated salt film at the pit surface.

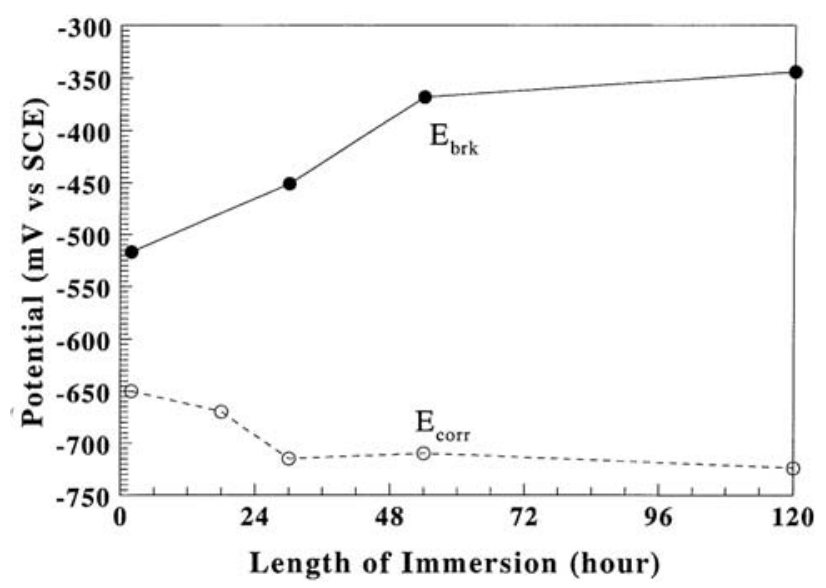

Fig. 8. Breakdown and corrosion potentials for a sample of initially untreated AA2024-T3 sample immersed in $0.1 \mathrm{M} \mathrm{NaCl}+8 \times 10^{-5}$ $\mathrm{M} \mathrm{K}_{2} \mathrm{CrO}_{4}$. A different sample was used for each exposure time. Reprinted with permission of the Electrochemical Society [6]. 
The conclusion that can be drawn from the thin film pitting experiments is that, for active pits under potentiostatic control, chromates do not have a large effect on the anodic dissolution unless the concentration is quite large. The effect of the undermined passive film on the dissolution kinetics is indirect in nature. These observations are in stark contrast to the considerable effects that chromates can have at low concentration during exposure at open circuit. Other evidence has indicated that chromates act as cathodic inhibitors, which would not be seen under potentiostatically controlled conditions [14].

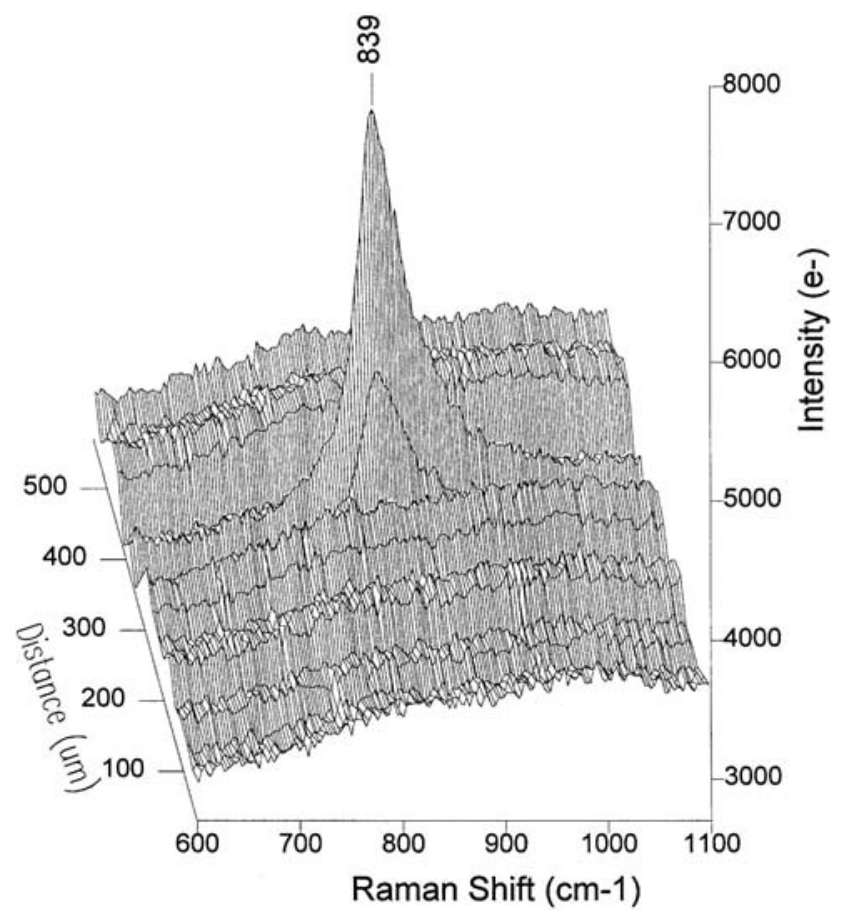

Fig. 9. Raman spectra around pit on sample immersed in 0.1 $\mathrm{M} \mathrm{NaCl}+8 \times 10^{-5} \mathrm{M} \mathrm{K}_{2} \mathrm{CrO}_{4}$ for 5 days. Reprinted with permission of the Electrochemical Society [6].

\section{Conclusions}

Chromate conversion coatings and chromates in solution have been studied by several different techniques. The following observations were made:

1. CCCs were shown to be spectroscopically similar to a synthetic mixed $\mathrm{Cr}(\mathrm{III}) / \mathrm{Cr}(\mathrm{VI})$ oxide.

2. Chromate was released from CCCs at a rate that decreased with increasing aging time in air.

3. Chromate released from a CCC was found to migrate to a nearby, uncoated Al 2024-T3 surface, form a Cr-enriched surface film, and increase the corrosion resistance of that surface.

4. Exposure of an uncoated Al 2024-T3 surface to a chloride solution containing dilute chromate resulted in an increase in the resistance to localized corrosion. 
5. The rate of growth of pits in thin Al films was only reduced by large amounts of chromate in solution. Chromate altered the nature of the passive film to make it more of a barrier to transport, thereby having an indirect effect on anodic dissolution rate.

6.

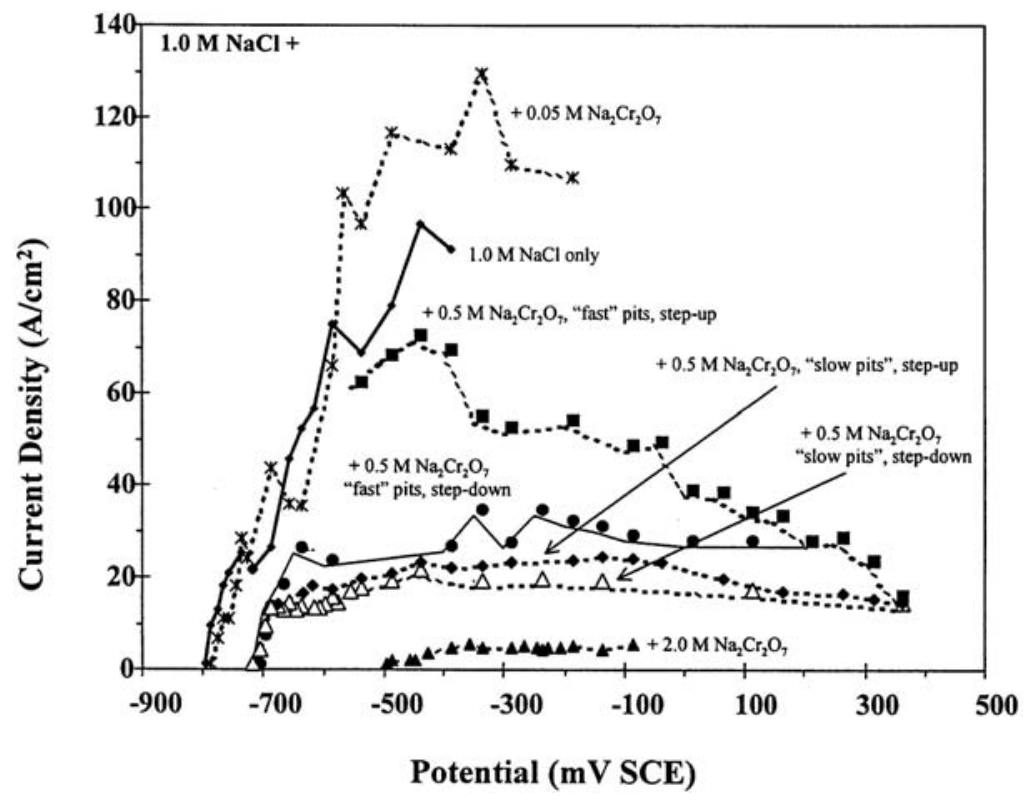

Fig. 10. Average anodic pit current density as a function of applied potential for pits in 209-nm-thick Al films in $1 \mathrm{M} \mathrm{NaCl}$ containing various amounts of $\mathrm{Na} 2 \mathrm{Cr} 2 \mathrm{O} 7$. Reprinted with permission of the Electrochemical Society [12].

\section{Acknowledgements}

This work was supported by Major H. DeLong at the United States Air Force Office of Scientific Research under contracts F49620-96-1-0479 and F49620-96-0042.

\section{References}

1. Alternatives to Chromium for Metal Finishing, Report No. 0273RE95, National Center for Manufacturing Sciences, Ann Arbor, 1995.

2. Report by the Air Force Blue Ribbon Advisory Panel on Aircraft Coatings, November 1995.

3. C. Edeleanu, U.R. Evans, Trans. Faraday Soc. 47 (1951) 1121.

4. M.W. Kendig, AJ. Davenport, H.S. Isaacs, Corros. Sci. 34 (1993) 41.

5. F.W. Lytle, R.B. Greegor, G.L. Bibbins, K.Y. Blohowiak, R.E. Smith, G.D. Tuss, Corros. Sci. 37 (1995) 349.

6. J. Zhao, G.S. Frankel, R.L. McCreery, J. Electrochem. Soc. 145 (1998) 2258.

7. L. Xia, R.L. McCreery, J. Electrochem. Soc. 145 (1998.) 3083.

8. G.S. Frankel, Corros. Sci. 30 (1990) 1203.

9. G.S. Frankel, J.O. Dukovic, B.M. Rush, V. Brusic, C.V. Jahnes, J. Electrochem. Soc. 139 (1992) 2196.

10. G.S. Frankel, R.C. Newman, C.V. Jahnes, M.A. Russak, J. Electrochem. Soc. 140 (1993) 2192.

11. G.S. Frankel, J.R. Scully, C.V. Jahnes, J. Electrochem. Soc 143 (1834) 1996. 
12. A. Sehgal, D. Lu, G.S. Frankel, J. Electrochem. Soc. 145 (1998) 2834.

13. J. Osborne, Chromate conversion coatings from a sol-gel perspective, Prog. Org. Coat., in press.

14. A. Sehgal, G.S. Frankel, B. Zoofan, S. Rokhlin, J. Electrochem. Soc. 147 (2000) 140. 